\title{
Assessment Tools for the Mental Health of School-Aged Children and Adolescents Exposed to Disaster: A Systematic Review (1988-2015)
}

\author{
Mi-Sun Lee ${ }^{1}$ and Soo-Young Bhang ${ }^{2}$ \\ 1 Department of Psychiatry, Eulji University Hospital, Seoul, Korea \\ ${ }^{2}$ Department of Psychiatry, Eulji University School of Medicine, Eulji University Hospital, Seoul, Korea
}

\begin{abstract}
Objectives: In this study, we aimed to conduct a systematic review of studies investigating psychosocial factors affecting children exposed to disasters.

Methods: In total, 140 studies were retrieved. The studies were published from 1988 to 2015 . A systematic review was performed using the PRISMA guidelines. MEDLINE, EMBASE, Cochrane Central, Web of Science, PsycINFO, PubMed, and Google Scholar were searched. Each database was searched using the following terms: 'Child,' 'Adolescent,' 'Youth,' 'Disaster, 'Posttraumatic,' 'Psychosocial,' 'Assessment,' 'Evaluation,' and 'Screening.' The identified studies were subjected to data extraction and appraisal.

Results: The database search identified 713 articles. Based on the titles and abstracts, the full texts of 118 articles were obtained. The findings of this review can be used as a basis for the design of a psychosocial evaluation tool for disaster preparedness.

Conclusion: Given the paramount importance of post-disaster evaluation and the weaknesses of current disaster evaluation tools, the need to develop valid and reliable tools and psychometric evaluations cannot be overstated. Our findings provide current evidence supporting various assessments in children, who are very vulnerable psychologically following disasters.
\end{abstract}

Key Words: Disaster; Mental health tool; Assessment; Children; Systematic review.

Received: January 12, 2018 / Revision: April 3, 2018 / Accepted: April 24, 2018

Address for correspondence: Soo-Young Bhang, Department of Psychiatry, Eulji University School of Medicine, Eulji University Hospital, 68 Hangeulbiseok-ro, Nowon-gu, Seoul 01830, Korea

Tel: +82-2-970-8303, Fax: +82-2-970-8429, E-mail: bsy1@eulji.ac.kr

\section{INTRODUCTION}

Disasters result in physical and psychosocial injuries and symptoms. A disaster management system focused primarily on medical needs was developed in the United States following the 9/11 terror attacks and Hurricane Katrina. ${ }^{1)}$ Disasters in particular lead to chronic mental health problems and have a profound impact on physical and mental health, ranging from mild injury to death. ${ }^{2)}$ In addition, disasters experienced by psychologically vulnerable children and adolescents lead to destructive behaviors and externalizing, which may result in numerous psychological, emotional, and behavioral disorders. ${ }^{3,4)}$ Therefore, mental health professionals should conduct appropriate mental health assessments in children and adolescents exposed to disasters. These assessments should be followed by effective high-risk interventions.

In the event of a disaster, rapid and efficient mental health

This is an Open Access article distributed under the terms of the Creative Commons Attribution Non-Commercial License (http://creativecommons.org/licenses/by-nc/4.0) which permits unrestricted non-commercial use, distribution, and reproduction in any medium, provided the original work is properly cited. assessments are needed to address emergencies. Effective disaster management is one of the main concerns of the World Health Organization (WHO) ${ }^{5}$ in its efforts to reduce and prevent post-traumatic stress disorder (PTSD). Nevertheless, research into the psychological responses of children and adolescents to disasters is still in the early stages. ${ }^{4)}$

The National Child Traumatic Stress Network (NCTSN) in the United States recommends the assessment of two critical elements when screening traumatized children: 1) exposure to potentially traumatic events/experiences, including traumatic loss, and 2) traumatic stress symptoms/reactions. Trauma screening is used to assess a wide range of experiences and to identify common reactions and symptoms of trauma (PTSD or dissociation) and other commonly reported difficulties (anger, behavior problems, depression, and anxiety). ${ }^{6}$ Nevertheless, studies have shown the inadequacy of standard guidelines and reliable measures used to assess the mental health of children and adolescents after a disaster. ${ }^{7)}$ Clinicians who conduct mental health assessments face many obstacles, as disaster environments are unpredictable and 
confusing in practice. Additionally, the post-disaster situation and diversity of research subjects complicate the selection of assessment tools. ${ }^{8)}$ Therefore, a comprehensive approach is needed.

We systematically reviewed the literature and here propose an appropriate set of directions for mental health evaluation in an emergency. The goal of this study was to provide methodological consistency and to perform a systematic literature review of mental health assessment tools for children and adolescents. The systematic literature review highlighted the need for a fair degree of accuracy and the development of standardized measures. Systematic reviews of research studies investigating mental health assessment following disasters represent major sources of psychological support for individuals and the society. ${ }^{3)}$ We sought to conduct an analysis of the standardized scales in order to develop evaluation resources for use in future large-scale disasters.

\section{METHODS}

We conducted a comprehensive search of online databases (Google Scholar, MEDLINE, Web of Science, ProQuest, Science Direct, Ovid, Scopus, Cochrane, and CINAHL) until 2015. We analyzed studies of disasters from 1988 to 2015 and reviewed research assessing the mental health of children and adolescents after disasters. We selected studies in English that included assessments related to disasters. We also selected reports of human medical research data. The Medical Subject Headings (MeSH) used in the search included the keywords 'Child,' 'Adolescent,' 'Youth, 'Disaster,' 'Posttraumatic,' 'Psychosocial,' 'Assessment,' 'Evaluation,' and 'Screening.'

After removal of duplicate articles, we selected 713 studies. Following a review of the titles and abstracts of the papers, 530 documents were excluded. We reviewed the entire contents of approximately 183 full articles and included stud-

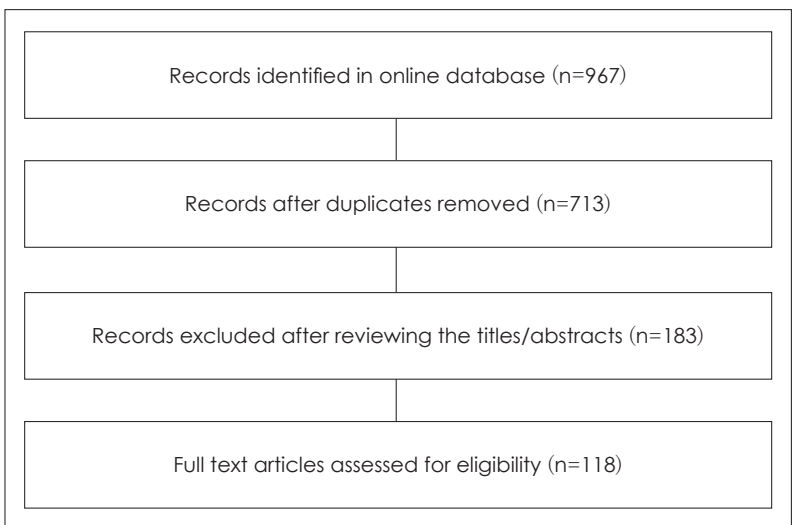

Fig. 1. Flowchart outlining the selection of studies. ies based on the agreement of both authors. Finally, 118 papers were included in the final review (Fig. 1).

The systematic literature review was conducted according to the Preferred Reporting Items for Systematic reviews and Meta-Analyses (PRISMA) guideline. PRISMA is an evidencebased minimum set of items for reporting systematic reviews, and is used as the basis for appraisal of published systematic reviews of different types of research. ${ }^{9}$ In this study, we used the PRISMA flow diagram, which depicts the flow of information through the different phases of a systematic review. This information include the numbers of articles identified, included, and excluded, and the reasons for exclusion.

\section{RESULTS}

A systematic review was conducted by searching mental health and medical databases. The results of the review are presented below.

In this study, we divided articles into Type I and Type II categories based on a previous study. ${ }^{10)}$ The articles in each category are presented in Table 1. Type I articles included those discussing natural disasters such as earthquakes, tsunamis, hurricanes, cyclones, floods, typhoons, and tornadoes. Type II articles discussed man-made disasters such as fires, sinkings, terrorist attacks, and explosions.

A total of 118 studies assessed the symptoms of PTSD, anxiety, depression, behavior, coping, and daily life in children and adolescents exposed to disaster. Thirty-one scales were used to assess the symptoms associated with PTSD, and 10 or more of the various scales assessed the following domains: anxiety, depression, structured clinical interview, and general psychopathology. In addition, one or more of the measures used assessed social support, coping, family relationships, attention, stress, routines, quality of life, cognitive function, somatization, health, emotion, attachment, control, behavior, and substance abuse. The mental health assessment tools in children according to the rater characteristics (Table 2) or Type of Disaster (Table 3 and 4) and the full names for the abbreviations of the scales after a disaster reviewed in this article (Table 5) are described in Table 2 through Table 5. The assessment tools for the children's mental health used in the well-known type I and type II disaster, Hurricane Katrina (2005) and 9/11 terrorist attack (2001), respectively, were presented in Supplementary Table 1 and 2 (in the online-only Data Supplement). In addition, the mental health assessment tools used for each disaster event presented in Supplementary Table 3-15 (in the online-only Data Supplement) (type I disaster) and Supplementary Table 16-22 (in the online-only Data Supplement) (type II disaster). 


\section{DISCUSSION}

Our review of the 118 selected studies revealed that 35 (29.67\%) of the studies used single scales. All other studies used up to 8 scales to assess mental health. ${ }^{11-14)}$
Depressive disorders are some of the most common psychological responses to trauma and stress. Depressive disorders in children and adolescents cause interpersonal problems and may affect developmental functions. Depressive symptoms should be monitored in children and adolescents

Table 1. Type I and Type I| disasters reviewed in this article

\begin{tabular}{|c|c|c|}
\hline Disaster type & Year & Event \\
\hline \multicolumn{3}{|l|}{ Type I } \\
\hline \multirow[t]{5}{*}{ Tsunami } & 2004 & Tsunami in Sri Lanka \\
\hline & 2004 & Tsunami in Thailand (Norwegian tourists) \\
\hline & 2004 & Tsunami in South-east Asia \\
\hline & 2004 & Tsunami in Aceh, Indonesia \\
\hline & 2011 & Tsunami in Higashi-Matsushima, Japan \\
\hline \multirow[t]{14}{*}{ Earthquake } & 1988 & Spitak earthquake in Armenia \\
\hline & 1988 & Earthquake in Armenia \\
\hline & 1995 & Earthquake in Kobe, Japan \\
\hline & 1999 & Earthquake in Athens \\
\hline & 1999 & Earthquake in Turkey \\
\hline & 1999 & Chi-Chi earthquake in Taiwan \\
\hline & 1999 & Parnitha earthquake in Greece \\
\hline & 1999 & Earthquake in Ano Liosia, Greece \\
\hline & 2003 & Earthquake in Bam, Iran \\
\hline & 2004 & Earthquake in Southern India \\
\hline & 2005 & Earthquake in Kashmir \\
\hline & 2009 & L'Aquila earthquake in Italy \\
\hline & 2011 & Earthquake in Yingjiang, China \\
\hline & 2011 & Van earthquake in Turkey \\
\hline \multirow[t]{4}{*}{ Hurricane } & 1989 & Hurricane Hugo in the Southeast United States \\
\hline & 1992 & Hurricane Andrew, USA \\
\hline & 1998 & Hurricane Mitch in Nicaragua \\
\hline & 2005 & Hurricane Katrina, USA \\
\hline \multirow[t]{3}{*}{ Cyclone } & 1999 & Super-cyclone in Orissa, India \\
\hline & 2006 & Cyclone Larry in North Queensland, Australia \\
\hline & - & Cyclone storms in Queensland, Australia \\
\hline Flood & 1998 & Flood in Hunan, China \\
\hline Typhoon & 2009 & Typhoon Morakot in Taiwan \\
\hline Tornado & 2011 & Tornado in the USA \\
\hline \multicolumn{3}{|l|}{ Type ॥ } \\
\hline \multirow[t]{6}{*}{ Fire } & 1988 & The discotheque fire in Göteborg, Sweden \\
\hline & 1994 & Bushfire in South Wales, Australia \\
\hline & 2000 & The explosion of a fireworks depot largely in the Netherlands \\
\hline & 2001 & A fire in a café in Volendam, the Netherlands \\
\hline & 2005 & Bushfires in South Australia \\
\hline & 2007 & Wildfire in Greece \\
\hline \multirow[t]{2}{*}{ Sinking } & 1988 & Jupiter sinking in Greece (on board were 391 British school children) \\
\hline & 2002 & A boat sinking in Tehran's city park \\
\hline \multirow[t]{2}{*}{ Terrorist attack } & 2001 & $9 / 11$ terrorist attack in New York \\
\hline & 2011 & Oslo terror attacks in Norway \\
\hline \multirow[t]{2}{*}{ Bombing } & 1995 & City bombing in Oklahoma, USA \\
\hline & 2013 & Boston Marathon bombing \\
\hline
\end{tabular}


exposed to disaster. ${ }^{4)}$ None of the studies reviewed used a single scale to assess depression or anxiety. This is consistent with the findings of Wang et al. ${ }^{15}$ A long-term follow-up study ${ }^{16)}$ investigated PTSD and depressive symptoms in children and adolescents over a period of about six and a half years after a disaster. Several studies have shown that mental health interventions during the early follow-up stages effectively reduce the prevalence of psychopathological problems in pediatric survivors. ${ }^{15)}$

Earthquakes were analyzed in a study ${ }^{16)}$ that used the Children's Post-Traumatic Stress Disorder-Reaction Index (CPTSDRI), the Depression Self-Rating Scale (DSRS), and other sim- ilar scales for follow-up. Of these scales, the University of California at Los Angeles PTSD Reaction Index (UCLA PTSD-RI) scale represents an appropriate tool for the assessment of children and adolescents in various disasters. Translated versions of this scale, which are available in many different languages, were shown to be cost-effective and userfriendly, and to facilitate effective management and rapid evaluation. ${ }^{4}$

A comparison of the 9/11 terror attacks and Hurricane Katrina revealed that only the CPTSD-RI and UCLA PTSD-RI were used as common evaluation tools. Until now, there has been no gold standard assessment used after a disaster. At

Table 2. Mental health assessment tools after the disaster in children according to the rater (self report, parent, teacher, and clinician)

\begin{tabular}{|c|c|c|c|c|}
\hline Symptoms/rater & Self-report scale & $\begin{array}{l}\text { Parents' } \\
\text { report scale }\end{array}$ & $\begin{array}{l}\text { Teacher's } \\
\text { report scale }\end{array}$ & Clinician's report scale \\
\hline PTSD & $\begin{array}{l}\text { AVE, CPSS, CPTSD-RI, CRIES, CRIES-13, } \\
\text { CSDC, DIS, KID-SAVE, LEC, LES, LSC-R, } \\
\text { NSA-R, NWS, PCL-C, PCL-S, PSPS, PSS, } \\
\text { PTCI, PTG, PTSD-RI, PTSS, SAVE, SRS-PTSD, } \\
\text { TESS, TSSC-CA, UCLA PTSD-RI, YPQ }\end{array}$ & IES, IES-R, WIP & & CAPS \\
\hline Diagnosis & & & & $\begin{array}{l}\text { C-DISC, ChIPS, CIDI, CSR, } \\
\text { DISC, DISC-PS, Kiddie-SADS- } \\
\text { L, MINI-KID, RECAP, SADS-L }\end{array}$ \\
\hline Anxiety & $\begin{array}{l}\text { ACQ-C, CASI, DASS, FSS-C, MASC-T, } \\
\text { RCADS-C, RCMAS, SCARED, SCARED-R- } \\
\text { CV, SCAS, STAI-C, TASC }\end{array}$ & RCADS-P, STAI & & ADIS-IV \\
\hline Depression & $\begin{array}{l}\text { BDI, CDI, DASS, DPS, DSRS, NCTSN, } \\
\text { RCADS-C, SDIC }\end{array}$ & $\begin{array}{l}\text { CES-D, } \\
\text { RCADS-P }\end{array}$ & & DISC \\
\hline $\begin{array}{l}\text { General } \\
\text { psychopathology }\end{array}$ & $\begin{array}{l}\text { APSC, BSI-18, CBQ, LASC, SCL-90-R, } \\
\text { SDQ, YSR }\end{array}$ & $\mathrm{CBCL}$ & C-TRF & PSC-II \\
\hline Social support & ISEL, MSPSS, SSRS, SSSC, SSSCA, TRICA-S & & & \\
\hline Type specific & EEQ, EES, ETQ, HURTE, PsySTART, WEQ & & & \\
\hline Coping & CCAC, NCSS, SSRS, WCQ, YCITT & & & \\
\hline Family & APGAR, CRPBI, FAD, FRM & & & \\
\hline Cognitive function & $M C Q-C$ & & & \\
\hline Attention & COWAT & BRIEF & & \\
\hline ADHD & & BRIEF & & \\
\hline Emotion & FMSS-EE & & & \\
\hline Stress & DASS, SASRQ & & & \\
\hline Routines & CRI, DLQ & & & \\
\hline Sleep & PSQI, SQ & & & \\
\hline Somatization & CSI & & & \\
\hline Health & GHQ-12 & & & \\
\hline Attachment & & IPPA & & \\
\hline Control & LCS & & & \\
\hline Behavior & YRBS & & & \\
\hline Quality of life & PedsQL, QoLQ & & & \\
\hline Substance & CRAFFT & & & \\
\hline Miscellaneous & $A B I, I U B Q, W T C$ & $R Q$ & TRF & \\
\hline
\end{tabular}

Acronyms are given in Table 5 
Table 3. Mental health assessment tools used after the Type I disaster in children

\begin{tabular}{|c|c|c|c|}
\hline Scale & Tsunami & Earthquake & $\begin{array}{l}\text { Hurricane } \\
\text { and Others }\end{array}$ \\
\hline APGAR & & & $\mathrm{O}^{23,24)}$ \\
\hline$A P Q$ & & & $\mathrm{O}^{13)}$ \\
\hline APSC & & & $\mathrm{O}^{25)}$ \\
\hline BDI (Beck) & & $\mathrm{O}^{26,27)}$ & \\
\hline BRIEF & & $\mathrm{O}^{14)}$ & \\
\hline CAPS & & $\mathrm{O}^{28,29)}$ & \\
\hline CASI & & $\mathrm{O}^{30,31)}$ & \\
\hline $\mathrm{CBCL}$ & & $\mathrm{O}^{32,33)}$ & \\
\hline$C B Q$ & & & $\mathrm{O}^{34)}$ \\
\hline CDI & $\mathrm{O}^{35-37)}$ & $\mathrm{O}^{26,30,31,38-41)}$ & \\
\hline CES-D & & $\mathrm{O}^{42)}$ & $\mathrm{O}^{24)}$ \\
\hline ChIPS & & $\mathrm{O}^{43)}$ & \\
\hline COWAT & & $\mathrm{O}^{14)}$ & \\
\hline CPSS & & $\mathrm{O}^{42,44)}$ & \\
\hline CPTSD-RI & $\mathrm{O}^{45)}$ & $\mathrm{O}^{16,26,27,30,31,38,40,46-48)}$ & $\mathrm{O}^{49-54)}$ \\
\hline CRAFFT & & & $\mathrm{O}^{34)}$ \\
\hline CRI & & & $\mathrm{O}^{13)}$ \\
\hline CRIES & $\mathrm{O}^{35-37)}$ & $\mathrm{O}^{55-57)}$ & \\
\hline CRIES-13 & & $\mathrm{O}^{39)}$ & \\
\hline CRPBI & & & $\mathrm{O}^{58)}$ \\
\hline CSDC & $\mathrm{O}^{59)}$ & & \\
\hline C-TRF & & & $\mathrm{O}^{24)}$ \\
\hline C-WISC & & $\mathrm{O}^{14)}$ & \\
\hline DASS & & $O^{44,60)}$ & \\
\hline DIS & & $\mathrm{O}^{61)}$ & \\
\hline DLQ & & $\mathrm{O}^{62}$ & \\
\hline DSRS & $\mathrm{O}^{63)}$ & $\mathrm{O}^{16,39,46,64,65)}$ & $\mathrm{O}^{66)}$ \\
\hline EEQ & & $\mathrm{O}^{67)}$ & \\
\hline EES & & $\mathrm{O}^{14)}$ & \\
\hline ETQ & & $\mathrm{O}^{39)}$ & \\
\hline FAD & & $\mathrm{O}^{26)}$ & \\
\hline FRM & & & $\mathrm{O}^{54)}$ \\
\hline GHQ-12 & $\mathrm{O}^{68)}$ & $\mathrm{O}^{26)}$ & \\
\hline HEQ & & & $\mathrm{O}^{13)}$ \\
\hline HRQOL & & $\mathrm{O}^{40)}$ & \\
\hline HURTE & & & $O^{49,69)}$ \\
\hline IES & & $\mathrm{O}^{32,38)}$ & \\
\hline IES-R & $\mathrm{O}^{59,70)}$ & & $\mathrm{O}^{24,71)}$ \\
\hline IPPA & & & $\mathrm{O}^{58)}$ \\
\hline ISEL & & & $\mathrm{O}^{13)}$ \\
\hline Kiddie-SADS-L & & $\mathrm{O}^{56)}$ & \\
\hline KIDS-SAVE & & & $O^{(3,69)}$ \\
\hline LASC & & & $\mathrm{O}^{72)}$ \\
\hline LCS & & $\mathrm{O}^{73)}$ & \\
\hline LEC & & & $\mathrm{O}^{49,50)}$ \\
\hline LSC-R & & & $\mathrm{O}^{25)}$ \\
\hline MASC-T & & & $\mathrm{O}^{71)}$ \\
\hline
\end{tabular}

Table 3. Mental health assessment tools used after the Type I disaster in children (continued)

\begin{tabular}{|c|c|c|c|}
\hline Scale & Tsunami & Earthquake & $\begin{array}{l}\text { Hurricane } \\
\text { and Others }\end{array}$ \\
\hline MCQ-C & & $\mathrm{O}^{31)}$ & \\
\hline MINI-KID & & $\mathrm{O}^{14)}$ & $\mathrm{O}^{23,24,71)}$ \\
\hline MSPSS & & $\mathrm{O}^{41)}$ & \\
\hline NCSS & & $\mathrm{O}^{73)}$ & \\
\hline NCTSN & & & $\mathrm{O}^{74)}$ \\
\hline NSA-R & & & $\mathrm{O}^{34)}$ \\
\hline PCL-C & & $\mathrm{O}^{73)}$ & \\
\hline PCL-S & & $\mathrm{O}^{60)}$ & \\
\hline PedsQL & & $\mathrm{O}^{40)}$ & \\
\hline PSC-II & $\mathrm{O}^{37)}$ & & \\
\hline PSPS & & $\mathrm{O}^{611}$ & \\
\hline PSQI & & $\mathrm{O}^{64)}$ & \\
\hline PsySTART & $\mathrm{O}^{63)}$ & & \\
\hline PTCl & & $\mathrm{O}^{56)}$ & \\
\hline PTG & $\mathrm{O}^{75)}$ & & \\
\hline PTSD-RI & & $\mathrm{O}^{76)}$ & $\mathrm{O}^{77.78)}$ \\
\hline PTSSC-15 & $\mathrm{O}^{79)}$ & $\mathrm{O}^{62,80-82)}$ & \\
\hline QoLQ & & $\mathrm{O}^{83)}$ & \\
\hline RCADS-C & & & $\mathrm{O}^{52,58)}$ \\
\hline RCADS-P & & & $\mathrm{O}^{58)}$ \\
\hline ROCFT & & $\mathrm{O}^{14)}$ & \\
\hline $\mathrm{RQ}$ & & $\mathrm{O}^{84)}$ & \\
\hline SAVE & & & $\mathrm{O}^{13,69)}$ \\
\hline SCARED & & $\mathrm{O}^{38)}$ & \\
\hline SCARED-R-CV & & $\mathrm{O}^{31)}$ & \\
\hline SCAS & & $\mathrm{O}^{39)}$ & \\
\hline SCL-90-R & & $\mathrm{O}^{43,84)}$ & $\mathrm{O}^{13)}$ \\
\hline$S D Q$ & $\mathrm{O}^{85)}$ & $\mathrm{O}^{38,57)}$ & $\mathrm{O}^{54,86,87)}$ \\
\hline SRS-PTSD & & $\mathrm{O}^{26)}$ & \\
\hline SSRS & & $\mathrm{O}^{56,64)}$ & \\
\hline SSSC & & & $\mathrm{O}^{69)}$ \\
\hline SSSCA & & & $\mathrm{O}^{49)}$ \\
\hline STAI & & $\mathrm{O}^{27-29,38)}$ & \\
\hline STAI-C & & $O^{26,30,31)}$ & \\
\hline Stroop & & $\mathrm{O}^{14)}$ & \\
\hline TASC & & & $\mathrm{O}^{52)}$ \\
\hline TESS & $\mathrm{O}^{45)}$ & & \\
\hline TMT-A & & $\mathrm{O}^{14)}$ & \\
\hline TRF & & & $\mathrm{O}^{78)}$ \\
\hline TRICA-S & & $\mathrm{O}^{88)}$ & \\
\hline TSSC-CA & & $\mathrm{O}^{67)}$ & \\
\hline UCLA PTSD-RI & $O^{63,70,89-91)}$ & $\mathrm{O}^{41,65,83,88)}$ & $\mathrm{O}^{13,69,92,93)}$ \\
\hline WIP & & $\mathrm{O}^{84)}$ & \\
\hline YPQ & & $\mathrm{O}^{84)}$ & \\
\hline YRBS & & & $\mathrm{O}^{74,94)}$ \\
\hline YSR & & $\mathrm{O}^{33)}$ & \\
\hline
\end{tabular}


Table 4. Mental health assessment tools used after the Type II disaster in children

\begin{tabular}{|c|c|c|c|c|}
\hline Scale & Fire & Sinking & Terrorist attack & Bombing \\
\hline$A B I$ & & & $\mathrm{O}^{95)}$ & \\
\hline$A C Q-C$ & $\mathrm{O}^{111}$ & & & \\
\hline ADIS-IV & $\mathrm{O}^{11)}$ & & & \\
\hline BDI (Berleson) & $\mathrm{O}^{11,96)}$ & $\mathrm{O}^{12,97-99)}$ & & \\
\hline BSI-18 & & & $\mathrm{O}^{100)}$ & \\
\hline C-DISC & & & $\mathrm{O}^{101)}$ & \\
\hline CAPS & $\mathrm{O}^{102)}$ & $\mathrm{O}^{12)}$ & & \\
\hline CASI & $\mathrm{O}^{11)}$ & & & \\
\hline $\mathrm{CBCL}$ & & & $\mathrm{O}^{103)}$ & \\
\hline CCAC & & & $\mathrm{O}^{101)}$ & \\
\hline CDI & & & $\mathrm{O}^{103)}$ & \\
\hline CES-D & & & $\mathrm{O}^{1011}$ & \\
\hline CIDI & & & $\mathrm{O}^{104)}$ & \\
\hline CPSS & & & $\mathrm{O}^{103)}$ & \\
\hline CPTSD-RI & $\mathrm{O}^{105)}$ & & $\mathrm{O}^{106)}$ & \\
\hline CRIES & $O^{107)}$ & & & \\
\hline CRIES-13 & $\mathrm{O}^{108)}$ & & & \\
\hline CSI & $\mathrm{O}^{107)}$ & & & \\
\hline CSR & $\mathrm{O}^{11)}$ & & & \\
\hline DASS & & & & $\mathrm{O}^{109)}$ \\
\hline DISC & & & $\mathrm{O}^{104,110-113)}$ & \\
\hline DISC-PS & $\mathrm{O}^{111}$ & & & \\
\hline DPS & & & $\mathrm{O}^{110,112)}$ & \\
\hline DSRS & $\mathrm{O}^{108)}$ & & & \\
\hline FMSS-EE & & & $\mathrm{O}^{95)}$ & \\
\hline FSS-C & & $\mathrm{O}^{97)}$ & & \\
\hline HURTE & $\mathrm{O}^{105)}$ & & & \\
\hline IES & $\mathrm{O}^{11,96,102)}$ & $\mathrm{O}^{12,98,99)}$ & & \\
\hline IES-R & & & $\mathrm{O}^{100)}$ & $\mathrm{O}^{114)}$ \\
\hline IUBQ & & & $\mathrm{O}^{101)}$ & \\
\hline Kiddie-SADS-L & & & $\mathrm{O}^{95)}$ & \\
\hline LES & & $\mathrm{O}^{12)}$ & & \\
\hline NWS & & & $\mathrm{O}^{111}$ & \\
\hline PSS & & $\mathrm{O}^{115)}$ & & \\
\hline PTSS & & & & $O^{116)}$ \\
\hline RCMAS & $\mathrm{O}^{11,96)}$ & $\mathrm{O}^{12,97-99)}$ & $\mathrm{O}^{103)}$ & \\
\hline RECAP & & $\mathrm{O}^{12)}$ & & \\
\hline SADS-L & & $\mathrm{O}^{117)}$ & & \\
\hline SASRQ & & & $\mathrm{O}^{100)}$ & \\
\hline SCARED & $\mathrm{O}^{107)}$ & & & \\
\hline SDIC & $\mathrm{O}^{107)}$ & & & \\
\hline$S D Q$ & $\mathrm{O}^{107,118)}$ & & & $\mathrm{O}^{109,119)}$ \\
\hline SSRS & & & $\mathrm{O}^{103)}$ & \\
\hline SSSC & & $\mathrm{O}^{12)}$ & & \\
\hline UCLA PTSD-RI & $\mathrm{O}^{102,118)}$ & & $\mathrm{O}^{111,113,120)}$ & $\mathrm{O}^{109,119)}$ \\
\hline$W C Q$ & & $\mathrm{O}^{12)}$ & & \\
\hline WEQ & $\mathrm{O}^{108)}$ & & & \\
\hline WTC & & & $\mathrm{O}^{121)}$ & \\
\hline YCITT & & & $\mathrm{O}^{122)}$ & \\
\hline YSR & $\mathrm{O}^{123)}$ & & $\mathrm{O}^{103)}$ & \\
\hline
\end{tabular}

Acronyms are given in Table 5 this time, it is necessary to create a consensus among specialists regarding the use of different approaches for specific disaster types or the use of domain scales in the event of a disaster in South Korea. ${ }^{7}$ Specific disaster types and symptoms, as well as variables such as sleep, concentration, cognitive function, daily life, and quality of life, should be initially evaluated.

The sources of information can be categorized as self-report, caregiver's report, teacher's report, and direct evaluation by a mental health professional. A self-report form is a type of questionnaire that is read by the respondents, who select their own responses. ${ }^{17)}$ Effective assessments should require the consideration of children's developmental issues and changes in cognitive capacity. ${ }^{18)}$ The Fear Survey Schedule for Children (FSS-C), the Hurricane-Related Traumatic Experience Questionnaire (HURTE), the Screen for Child Anxiety Related Emotional Disorders (SCARED), the Screen for Adolescent Violence Exposure (SAVE), and the State and Trait Anxiety Inventory for Children (STAI-C) are usually used in self-report questionnaires, which children and adolescents respond to by themselves. However, self-report questionnaires to which school-aged children respond themselves have the disadvantage of allowing the respondent to reduce his or her externalizing symptoms. In addition, cases wherein school-aged children or adolescents are not well aware of their psychiatric symptoms should be noted by clinicians, who should then conduct the evaluation.

Parent-reported questionnaires may be categorized as follows: those that assess the parents' psychological symptoms, and those that allow parents to respond by observing their child's behavior. Examples of questionnaires assessing the parents' symptoms are the Impact of Event Scale-Revised (IES$\mathrm{R})$, the Watson Interview for PTSD of adults (WIP), and the Center for Epidemiological Studies Depression Scale (CES-D). Parents and teachers are considered reliable observers for the evaluation of the behavior of children and adolescents. ${ }^{19)}$ In our review, many parents reported such observations using the Children's Report of Parent Behavior Inventory (CRPBI); the Revised Child Anxiety and Depression Scales, Parent Version(RCADS-P); Rutter's Questionnaire, parent's version (RQ); and the Inventory of Parent and Peer Attachment (IPPA).

In the present study, we found that Achenbach's Teacher's Report Form (TRF) and the Chinese version of the TRF (CTRF) were used only as measures reported by the teacher. However, as reported previously, ${ }^{20)}$ they might underestimate internalizing symptoms, pain, and anger in children and adolescents. This suggests the need for careful interpretation of such reports.

Direct evaluation by mental health professionals is highly 
Table 5. Mental health assessment scales after a disaster reviewed in this article

Mental health assessment scales

$\mathrm{ABI}=$ Assessment of Behavioral Inhibition

$A C Q-C=$ the Anxiety Control Questionnaire for Children

ADIS-IV=the Anxiety Disorders Interview Schedule for DSM-IV (child and parent versions)

APGAR=Family APGAR Index-measures subjects' satisfaction with family support

$A P Q=A l a b a m a$ Parenting Questionnaire

APSC=the Adolescent Psychopathology Scale-Short Form

$\mathrm{AVE}=$ the Screen for Adolescent Violence Exposure

$\mathrm{BDI}=$ Birleson Depression Inventory

$\mathrm{BDI}=$ Beck Depression Inventory

$B R I E F=$ the Behavior Rating Scale of Executive Function, Parent Form for School Age Children

BSI-18=the Brief Symptom Inventory-18

C-DISC=Computer Diagnostic Interview Schedule for Children-IV

CAPS=Clinician Administered Posttraumatic Stress Disorder Scale

CASI=Childhood Anxiety Sensitivity Index

$\mathrm{CBCL}=$ Child Behavior Checklist

$\mathrm{CBQ}=$ Conflict Behavior Questionnaire Short Form

$\mathrm{CCAC}=$ the version of the Children's Coping Assistance Checklist

$\mathrm{CDI}=$ Children's Depression Inventory

CES-D=the Center for Epidemiological Studies Depression Scale

ChIPS=Children's Interview for Psychiatric Syndromes

CIDI=the Composite International Diagnostic Interview

COWAT=the Animal Naming Test of the Controlled Oral Word Association Test

CPSS $=$ Child PTSD Symptom Scale

CPTSD-RI=Children's Post-Traumatic Stress Disorder-Reaction Index

CRAFFT $=a$ standardized and valid 6-item self-report screen for adolescent substance-related problems and disorders

CRI=Child Routines Inventory

CRIES=Children's Impact of Events Scale

CRIES-13=Children's Revised Impact of Event Scale

CRPBI=the Children's Report of Parent Behavior Inventory

CSDC=the Child Stress Disorder Checklist

CSI=Children's Somatization Inventory

$\mathrm{CSR}=$ Clinical Severity Rating

C-TRF=the Chinese version of the Teacher's Report Form

C-WISC $=$ Chinese Wechsler Intelligence Scale for Children

DASS=Depression Anxiety and Stress Scales

DIS=Disaster Impact Scale

DISC=Diagnostic Interview Schedule for Children

DISC=the depression scale of the Diagnostic Predictive Scales derived from the NIMH Diagnostic Interview Scale for Children

DISC-PS=the Diagnostic Interview Schedule for Children-Predictive Scales

$D L Q=$ the Daily Life Questionnaire

DPS=Depression Predictive Scales

DSRS=Depression Self-Rating Scale

$\mathrm{EEQ}=$ the Earthquake Experience questionnaire

$\mathrm{EES}=$ Earthquake-related Experience Scale

$\mathrm{ETQ}=$ Earthquake Trauma Questionnaire

FAD $=$ McMaster Family Assessment Device

FMSS-EE=Five-Minute-Speech Sample Measure of Expressed Emotion

FRM=the Family Resilience Measure 
Table 5. Mental health assessment scales after a disaster reviewed in this article (continued)

Mental health assessment scales

FSS-C=Fear Survey Schedule for Children (revised form)

GHQ-12=General Health Questionnaire

$\mathrm{HEQ}=$ Hurricane Exposure Questionnaire

HRQOL=Health-related Quality of Life

HURTE=Hurricane-Related Traumatic Experience Questionnaire

IES=Impact of Events Scale

IES-R=the Impact of Event Scale Revised

IPPA=the Inventory of Parent and Peer Attachment

ISEL=Interpersonal Support and Evaluation List

IUBQ=the Inter-group Understanding or Bias Questionnaire

Kiddie-SADS-L=Kiddie Schedule for Affective Disorders and Schizophrenia for School-Age Children Lifetime version

KID-SAVE=Screen for Adolescent Violence Exposure (8-10 year)

LASC=the Los Angeles Symptom Checklist, adolescent version

LCS=Locus of Control Scale

LEC=Life Events Checklist

LES=Life Events Scale

LSC-R=the Life Stressor Checklist-Revised

MASC-T=Taiwanese version of the Multi-dimensional Anxiety Scale for Children

MCQ-C=Meta cognitions Questionnaire for Children

MINI-KID=the Mini-International Neuropsychiatric Interview for Children and Adolescents

MSPSS=Multidimensional Scale of Perceived Social Support

NCSS $=$ a native Coping Styles Scale

NCTSN assessment scale=the validated UCLA PTSD Index and includes a number of questions regarding depressive symptoms

NSA-R=The National Survey of Adolescents-Replication PTSD module

NWS=National Women's Study PTSD module

PCL-C=the PTSD Checklist-Civilian Chinese Version

PCL-S=PTSD Checklist-Specific Stressor Version

PedsQL=Pediatric Quality of Life Inventory TM 4.0 of the Chinese version

PSC-II=Pediatric Symptom Checklists part II

PSPS=the children's Perceived Stress Performance Scale

PSQI=Pittsburgh Sleep Quality Index

PSS=Post-Traumatic Stress Disorder Symptom Scale

PsySTART =a tsunami-modified version of the PsySTART Rapid Triage System

PTCl=Post-traumatic Cognitions Inventory

PTG=Post Traumatic Growth

PTSD-RI=Posttraumatic Stress Disorder Reaction Index

PTSS=the Posttraumatic Stress Symptom Scale

QoLQ=Quality of Life Questionnaire

RCADS-C=the Revised Child Anxiety and Depression Scales, Child Version

RCADS-P=the Revised Child Anxiety and Depression Scales, Parent Version

RCMAS=Revised Children's Manifest Anxiety Scale

RECAP =the Retrospective Experiences and Child and Adolescent Psychopathology interview

ROCFT=the Rey-Osterrieth Complex Figure Test

$R Q=$ Rutter's questionnaire, parent's version

SADS-L=the Schedule for Affective Disorders and Schizophrenia Lifetime Version

SASRQ $=$ Stanford Acute Stress Reaction Questionnaire

$S A V E=S c r e e n$ for Adolescent Violence Exposure (11-16 year)

SCARED=Screen for Child Anxiety Related Emotional Disorders 
Table 5. Mental health assessment scales after a disaster reviewed in this article (continued)

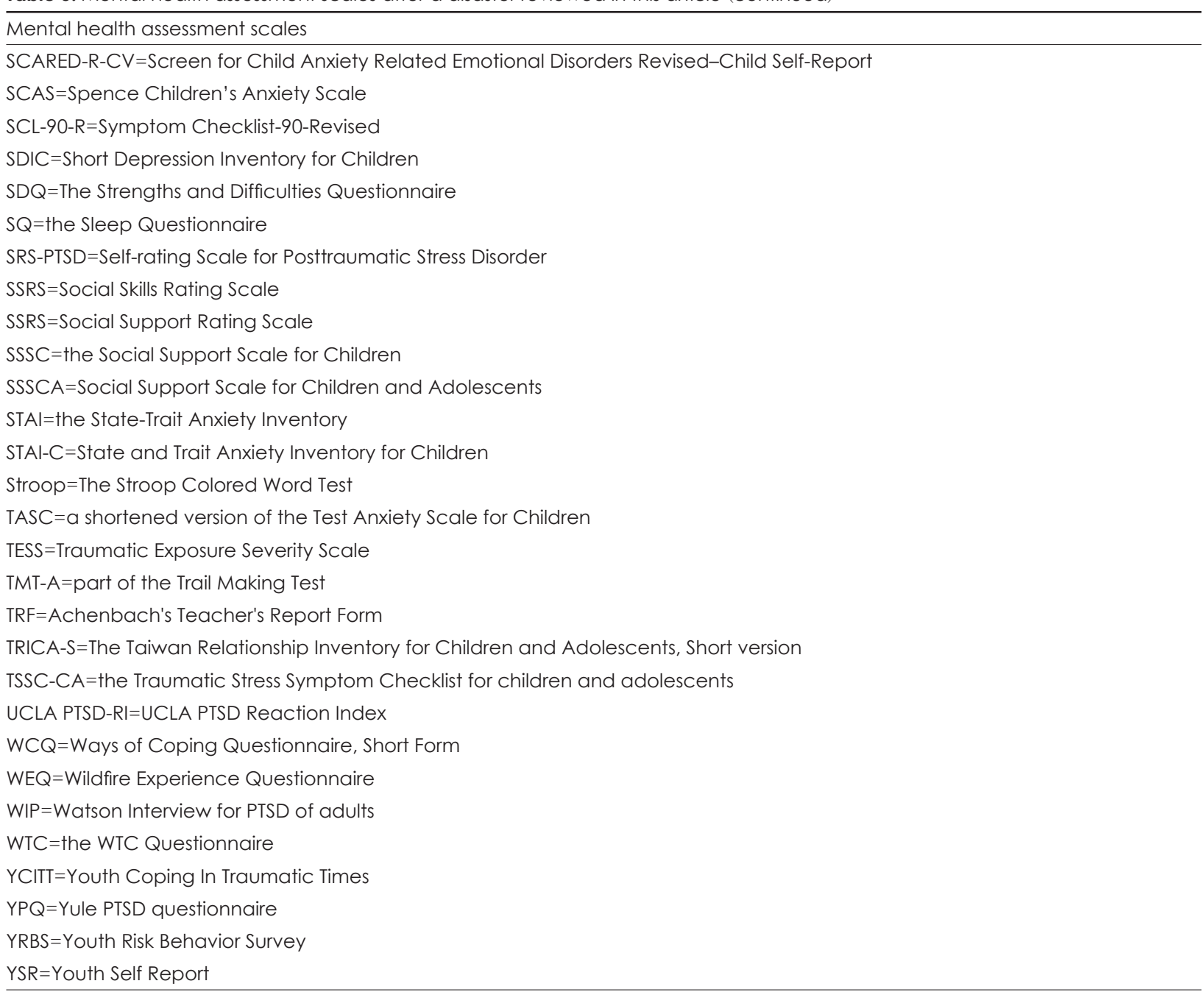

reliable. For instance, the Clinician-Administered Posttraumatic Stress Disorder Scale (CAPS), the Kiddie Schedule for Affective Disorders and Schizophrenia for School-Age Children Lifetime version (Kiddie-SADS-L), the Mini-International Neuropsychiatric Interview for Children and Adolescents (MINI-KID), and the Retrospective Experiences and Child and Adolescent Psychopathology interview (RECAP) are used as assessment scales by clinicians. Nevertheless, direct evaluations by mental health professionals were available in only a few studies.

For children and adolescents exposed to disasters, monitoring is based on the evaluation used, and subsequent intervention promotes recovery. Effective provision of mental health services and an integrated system facilitate the management of psychosocial challenges in children and adolescents. ${ }^{21)}$ Appropriate and timely interventions in communities may result in positive developmental impacts in young patients. Therefore, it is important to use an evaluation tool with high reliability and validity. A brief screening test followed by an in-depth assessment to select high-risk groups should be systematized. In addition, the cost of intervention following an emergency should be reduced. Mental healthrelated assessments are affected by the numbers of research designs and subjects. The scale that is used should be selected carefully to provide appropriate and critical feedback regarding the functional status and diagnosis of the subject. ${ }^{8)}$

The limitations of this study are as follows. The systematic literature review included an extensive search only for articles written in English. This means that some important research results may have been omitted. In addition, analysis of the scales used for different types of disasters may have been restricted due to the limited number of relevant studies. Furthermore, the final selection of articles included only those pertaining to school-aged children and adolescents. As such, evaluation items and tools used to assess individuals in early childhood were not analyzed. Therefore, a system- 
atic review of the literature on infants and preschoolers should be conducted in a subsequent study. Nevertheless, our study discusses mental health assessment tools for potential application following disasters and suggests recommendations for clinical settings. ${ }^{22)}$

\section{CONCLUSION}

Studies involving disaster evaluation highlight the behavioral and mental health impacts of the disaster. The results of this study have major implications for systematic mental health assessments and interventions administered to children and adolescents, as well as survivors of disasters in the future. It may thus serve as a basis for subsequent studies and for responses to policy measures.

\section{Supplementary Materials}

The online-only Data Supplement is available with this article at https://doi.org/10.5765/jkacap.180002.

\section{Acknowledgments}

This study was supported by a grant from the Korean Mental Health Technology R\&D Project, Ministry of Health \& Welfare, Republic of Korea (HM15C1058).

\section{Conflicts of Interest}

The authors have no financial conflicts of interest.

\section{REFERENCES}

1) Gold JI, Montano Z, Shields S, Mahrer NE, Vibhakar V, Ybarra T, et al. Pediatric disaster preparedness in the medical setting: integrating mental health. Am J Disaster Med 2009;4:137-146.

2) Garbern SC, Ebbeling LG, Bartels SA. A systematic review of health outcomes among disaster and humanitarian responders. Prehosp Disaster Med 2016;31:635-642.

3) Castaño García T, Vega Díaz C, Cernuda Martínez JA. Emotional disorders in children victims of natural disasters. Rev Enferm 2016;39:18-29.

4) Balaban V. Psychological assessment of children in disasters and emergencies. Disasters 2006;30:178-198.

5) Ardalan A, Kandi M, Talebian MT, Khankeh H, Masoumi G, Mohammadi R, et al. Hospitals safety from disasters in I.R.iran: the results from assessment of 224 hospitals. PLoS Curr 2014;6.

6) National Child Traumatic Stress Network. Empirically supported treatments and promising practices. 2005. Los Angeles/Durham: Author. [cited 2014 March 10]. Available from URL: https:// www.nctsn.org/resources/topics/treatments-that-work/promisingpractices.

7) Heidaranlu E, Ebadi A, Khankeh HR, Ardalan A. Hospital Disaster Preparedness Tools: a systematic review. PLoS Curr 2015;7.

8) Pfefferbaum B, Noffsinger MA, Sherrieb K, Norris FH. Framework for research on children's reactions to disasters and terrorist events. Prehosp Disaster Med 2012;27:567-576.

9) Moher D, Liberati A, Tetzlaff J, Altman DG; PRISMA Group. Preferred reporting items for systematic reviews and meta-analyses: the PRISMA statement. J Clin Epidemiol 2009;62:1006-1012.

10) Hoven CW, Duarte CS, Turner B, Mandell DJ. Child mental health in the aftermath of disaster: a review of PTSD studies. In: Neria Y, Galea S, Norris FH, editors. Mental health and disasters. Cam- bridge: Cambridge University Press;2009. p.218-232.

11) McDermott BM, Palmer LJ. Post-disaster service provision following proactive identification of children with emotional distress and depression. Aust N Z J Psychiatry 1999;33:855-863.

12) Udwin O, Boyle S, Yule W, Bolton D, O'Ryan D. Risk factors for long-term psychological effects of a disaster experienced in adolescence: predictors of post traumatic stress disorder. J Child Psychol Psychiatry 2000;41:969-979.

13) Kelley ML, Self-Brown S, Le B, Bosson JV, Hernandez BC, Gordon AT. Predicting posttraumatic stress symptoms in children following Hurricane Katrina: a prospective analysis of the effect of parental distress and parenting practices. J Trauma Stress 2010;23: $582-590$.

14) Ma X, Liu X, Hu X, Qiu C, Wang Y, Huang Y, et al. Risk indicators for post-traumatic stress disorder in adolescents exposed to the 5.12 Wenchuan earthquake in China. Psychiatry Res 2011;189:385391.

15) Wang CW, Chan CL, Ho RT. Prevalence and trajectory of psychopathology among child and adolescent survivors of disasters: a systematic review of epidemiological studies across 1987-2011. Soc Psychiatry Psychiatr Epidemiol 2013;48:1697-1720.

16) Goenjian AK, Walling D, Steinberg AM, Roussos A, Goenjian HA, Pynoos RS. Depression and PTSD symptoms among bereaved adolescents 6(1/2) years after the 1988 Spitak earthquake. J Affect Disord 2009;112:81-84.

17) Victor J. The SAGE dictionary of social research methods. London: SAGE Publications;2006.

18) Liu H, Hays RD, Marcus M, Coulter I, Maida C, Ramos-Gomez F, et al. Patient-reported oral health outcome measurement for children and adolescents. BMC Oral Health 2016;16:95.

19) Irwin DE, Gross HE, Stucky BD, Thissen D, DeWitt EM, Lai JS, et al. Development of six PROMIS pediatrics proxy-report item banks. Health Qual Life Outcomes 2012;10:22.

20) Jensen PS, Rubio-Stipec M, Canino G, Bird HR, Dulcan MK, Schwab-Stone ME, et al. Parent and child contributions to diagnosis of mental disorder: are both informants always necessary? J Am Acad Child Adolesc Psychiatry 1999;38:1569-1579.

21) Somasundaram DJ, van de Put WA. Management of trauma in special populations after a disaster. J Clin Psychiatry 2006;67 Suppl 2:64-73.

22) Lai BS, Esnard AM, Lowe SR, Peek L. Schools and disasters: safety and mental health assessment and interventions for children. Curr Psychiatry Rep 2016;18:109.

23) Tang TC, Yen CF, Cheng CP, Yang P, Chen CS, Yang RC, et al. Suicide risk and its correlate in adolescents who experienced typhooninduced mudslides: a structural equation model. Depress Anxiety 2010;27:1143-1148.

24) Yang P, Yen CF, Tang TC, Chen CS, Yang RC, Huang MS, et al. Posttraumatic stress disorder in adolescents after Typhoon Morakot-associated mudslides. J Anxiety Disord 2011;25:362-368.

25) Robertson AA, Morse DT, Baird-Thomas C. Hurricane Katrina's impact on the mental health of adolescent female offenders. Anxiety Stress Coping 2009;22:433-448.

26) Kiliç EZ, Ozgüven HD, Sayil I. The psychological effects of parental mental health on children experiencing disaster: the experience of Bolu earthquake in Turkey. Fam Process 2003;42:485495.

27) Karakaya I, Ağaoğlu B, Coşkun A, Sişmanlar SG, Yildiz Oc O. The symptoms of PTSD, depression and anxiety in adolescent students three and a half years after the Marmara earthquake. Turk Psikiyatri Derg 2004;15:257-263.

28) Ekşi A, Braun KL, Ertem-Vehid H, Peykerli G, Saydam R, Toparlak D, et al. Risk factors for the development of PTSD and depression among child and adolescent victims following a 7.4 magnitude earthquake. Int J Psychiatry Clin Pract 2007;11:190-199. 
29) Eksi A, Braun KL. Over-time changes in PTSD and depression among children surviving the 1999 Istanbul earthquake. Eur Child Adolesc Psychiatry 2009;18:384-391.

30) Kiliç EZ, Kiliç C, Yilmaz S. Is anxiety sensitivity a predictor of PTSD in children and adolescents? J Psychosom Res 2008;65:8186.

31) Kadak MT, Nasıroğlu S, Boysan M, Aydın A. Risk factors predicting posttraumatic stress reactions in adolescents after 2011 Van earthquake. Compr Psychiatry 2013;54:982-990.

32) John PB, Russell S, Russell PS. The prevalence of posttraumatic stress disorder among children and adolescents affected by tsunami disaster in Tamil Nadu. Disaster Manag Response 2007;5:3-7.

33) Feo P, Di Gioia S, Carloni E, Vitiello B, Tozzi AE, Vicari S. Prevalence of psychiatric symptoms in children and adolescents one year after the 2009 L'Aquila earthquake. BMC Psychiatry 2014;14: 270.

34) Sumner JA, Pietrzak RH, Danielson CK, Adams ZW, Ruggiero KJ. Elucidating dimensions of posttraumatic stress symptoms and their functional correlates in disaster-exposed adolescents. J Psychiatr Res 2014;59:85-92.

35) Piyasil V, Ketuman P, Plubrukarn R, Jotipanut V, Tanprasert S, Aowjinda S, et al. Post traumatic stress disorder in children after tsunami disaster in Thailand: 2 years follow-up. J Med Assoc Thai 2007;90:2370-2376

36) Piyasil V, Ketumarn P, Prubrukarn R, Pacharakaew S, Dumrongphol H, Rungsri S, et al. Psychiatric disorders in children at one year after the tsunami disaster in Thailand. J Med Assoc Thai 2008;91 Suppl 3:S15-S20.

37) Piyasil V, Ketumarn P, Prubrukarn R, Ularntinon S, Sitdhiraksa $\mathbf{N}$, Pithayaratsathien N, et al. Post-traumatic stress disorder in children after the tsunami disaster in Thailand: a 5-year follow-up. J Med Assoc Thai 2011;94 Suppl 3:S138-S144.

38) Kolaitis G, Kotsopoulos J, Tsiantis J, Haritaki S, Rigizou F, Zacharaki L, et al. Posttraumatic stress reactions among children following the Athens earthquake of September 1999. Eur Child Adolesc Psychiatry 2003;12:273-280.

39) Giannopoulou I, Strouthos M, Smith P, Dikaiakou A, Galanopoulou V, Yule W. Post-traumatic stress reactions of children and adolescents exposed to the Athens 1999 earthquake. Eur Psychiatry 2006;21:160-166.

40) Zhang N, Zhang Y, Wu K, Zhu Z, Dyregrov A. Factor structure of the Children's Revised Impact of Event Scale among children and adolescents who survived the 2008 Sichuan earthquake in China. Scand J Psychol 2011;52:236-241.

41) Geng F, Fan F, Mo L, Simandl I, Liu X. Sleep problems among adolescent survivors following the 2008 Wenchuan earthquake in China: a cohort study. J Clin Psychiatry 2013;74:67-74

42) Jia Z, Shi L, Duan G, Liu W, Pan X, Chen Y, et al. Traumatic experiences and mental health consequences among child survivors of the 2008 Sichuan earthquake: a community-based follow-up study. BMC Public Health 2013;13:104.

43) Hsu CC, Chong MY, Yang P, Yen CF. Posttraumatic stress disorder among adolescent earthquake victims in Taiwan. J Am Acad Child Adolesc Psychiatry 2002;41:875-881.

44) Wang R, Wang L, Li Z, Cao C, Shi Z, Zhang J. Latent structure of posttraumatic stress disorder symptoms in an adolescent sample one month after an earthquake. J Adolesc 2013;36:717-725.

45) Agustini EN, Asniar I, Matsuo H. The prevalence of long-term posttraumatic stress symptoms among adolescents after the tsunami in Aceh. J Psychiatr Ment Health Nurs 2011;18:543-549.

46) Goenjian AK, Walling D, Steinberg AM, Karayan I, Najarian LM, Pynoos R. A prospective study of posttraumatic stress and depressive reactions among treated and untreated adolescents 5 years after a catastrophic disaster. Am J Psychiatry 2005;162:2302-2308.

47) Bal A, Jensen B. Post-traumatic stress disorder symptom clusters in Turkish child and adolescent trauma survivors. Eur Child Adolesc Psychiatry 2007;16:449-457.

48) Pynoos RS, Goenjian A, Tashjian M, Karakashian M, Manjikian R, Manoukian G, et al. Post-traumatic stress reactions in children after the 1988 Armenian earthquake. Br J Psychiatry 1993;163:239247.

49) Moore KW, Varela RE. Correlates of long-term posttraumatic stress symptoms in children following Hurricane Katrina. Child Psychiatry Hum Dev 2010;41:239-250.

50) Weems CF, Taylor LK, Cannon MF, Marino RC, Romano DM, Scott BG, et al. Post traumatic stress, context, and the lingering effects of the Hurricane Katrina disaster among ethnic minority youth. J Abnorm Child Psychol 2010;38:49-56.

51) Taylor LK, Weems CF. Cognitive-behavior therapy for disaster-exposed youth with posttraumatic stress: results from a multiplebaseline examination. Behav Ther 2011;42:349-363.

52) Weems CF, Scott BG, Taylor LK, Cannon MF, Romano DM, Perry AM. A theoretical model of continuity in anxiety and links to academic achievement in disaster-exposed school children. Dev Psychopathol 2013;25:729-737.

53) Weems CF, Graham RA. Resilience and trajectories of posttraumatic stress among youth exposed to disaster. J Child Adolesc Psychopharmacol 2014;24:2-8.

54) McDermott BM, Cobham VE, Berry H, Stallman HM. Vulnerability factors for disaster-induced child post-traumatic stress disorder: the case for low family resilience and previous mental illness. Aust N Z J Psychiatry 2010;44:384-389.

55) Tian W, Jia Z, Duan G, Liu W, Pan X, Guo Q, et al. Longitudinal study on health-related quality of life among child and adolescent survivors of the 2008 Sichuan earthquake. Qual Life Res 2013;22: 745-752.

56) Ying LH, Wu XC, Lin CD, Chen C. Prevalence and predictors of posttraumatic stress disorder and depressive symptoms among child survivors 1 year following the Wenchuan earthquake in China. Eur Child Adolesc Psychiatry 2013;22:567-575.

57) Ayub M, Poongan I, Masood K, Gul H, Ali M, Farrukh A, et al. Psychological morbidity in children 18 months after Kashmir Earthquake of 2005. Child Psychiatry Hum Dev 2012;43:323-336.

58) Costa NM, Weems CF, Pina AA. Hurricane Katrina and youth anxiety: the role of perceived attachment beliefs and parenting behaviors. J Anxiety Disord 2009;23:935-941.

59) Dyb G, Jensen TK, Nygaard E. Children's and parents' posttraumatic stress reactions after the 2004 tsunami. Clin Child Psychol Psychiatry 2011;16:621-634.

60) Wang L, Long D, Li Z, Armour C. Posttraumatic stress disorder symptom structure in Chinese adolescents exposed to a deadly earthquake. J Abnorm Child Psychol 2011;39:749-758.

61) Sahin NH, Batigün AD, Yilmaz B. Psychological symptoms of Turkish children and adolescents after the 1999 earthquake: exposure, gender, location, and time duration. J Trauma Stress 2007;20: 335-345.

62) Usami M, Iwadare $Y$, Watanabe K, Kodaira M, Ushijima H, Tanaka T, et al. Analysis of changes in traumatic symptoms and daily life activity of children affected by the 2011 Japan earthquake and tsunami over time. PLoS One 2014;9:e88885.

63) Thienkrua W, Cardozo BL, Chakkraband ML, Guadamuz TE, Pengjuntr W, Tantipiwatanaskul P, et al. Symptoms of posttraumatic stress disorder and depression among children in tsunamiaffected areas in southern Thailand. JAMA 2006;296:549-559.

64) Yang R, Xiang YT, Shuai L, Qian Y, Lai KY, Ungvari GS, et al. Executive function in children and adolescents with posttraumatic stress disorder 4 and 12 months after the Sichuan earthquake in China. J Child Psychol Psychiatry 2014;55:31-38.

65) Roussos A, Goenjian AK, Steinberg AM, Sotiropoulou C, Kakaki M, Kabakos C, et al. Posttraumatic stress and depressive reactions 
among children and adolescents after the 1999 earthquake in Ano Liosia, Greece. Am J Psychiatry 2005;162:530-537.

66) Goenjian AK, Molina L, Steinberg AM, Fairbanks LA, Alvarez ML, Goenjian HA, et al. Posttraumatic stress and depressive reactions among Nicaraguan adolescents after hurricane Mitch. Am J Psychiatry 2001:158:788-794.

67) Kiliç C, Kiliç EZ, Aydin IO. Effect of relocation and parental psychopathology on earthquake survivor-children's mental health. J Nerv Ment Dis 2011;199:335-341.

68) Uttervall M, Hultman CM, Ekerwald H, Lindam A, Lundin T. After the flood: resilience among tsunami-afflicted adolescents. Nord J Psychiatry 2014;68:38-43.

69) Self-Brown S, Lai BS, Thompson JE, McGill T, Kelley ML. Posttraumatic stress disorder symptom trajectories in Hurricane Katrina affected youth. J Affect Disord 2013;147:198-204.

70) Jensen TK, Dyb G, Nygaard E. A longitudinal study of posttraumatic stress reactions in Norwegian children and adolescents exposed to the 2004 tsunami. Arch Pediatr Adolesc Med 2009;163: 856-861

71) Yen CF, Tang TC, Yang P, Chen CS, Cheng CP, Yang RC, et al. A multidimensional anxiety assessment of adolescents after Typhoon Morakot-associated mudslides. J Anxiety Disord 2011;25:106-111.

72) Overstreet S, Salloum A, Badour C. A school-based assessment of secondary stressors and adolescent mental health 18 months post-Katrina. J Sch Psychol 2010;48:413-431.

73) Zhang W, Liu H, Jiang X, Wu D, Tian Y. A longitudinal study of posttraumatic stress disorder symptoms and its relationship with coping skill and locus of control in adolescents after an earthquake in China. PLoS One 2014;9:e88263.

74) Kronenberg ME, Hansel TC, Brennan AM, Osofsky HJ, Osofsky JD, Lawrason B. Children of Katrina: lessons learned about postdisaster symptoms and recovery patterns. Child Dev 2010;81:12411259.

75) Hafstad GS, Gil-Rivas V, Kilmer RP, Raeder S. Parental adjustment, family functioning, and posttraumatic growth among Norwegian children and adolescents following a natural disaster. Am J Orthopsychiatry 2010;80:248-257.

76) Uemoto M, Asakawa A, Takamiya S, Asakawa K, Inui A. Kobe earthquake and post-traumatic stress in school-aged children. Int J Behav Med 2012;19:243-251.

77) Lonigan CJ, Shannon MP, Taylor CM, Finch AJ Jr, Sallee FR. Children exposed to disaster: II. risk factors for the development of post-traumatic symptomatology. J Am Acad Child Adolesc Psychiatry 1994;33:94-105.

78) Shaw JA, Applegate B, Schorr C. Twenty-one-month follow-up study of school-age children exposed to Hurricane Andrew. J Am Acad Child Adolesc Psychiatry 1996;35:359-364.

79) Kuwabara H, Araki T, Yamasaki S, Ando S, Kano Y, Kasai K. Regional differences in post-traumatic stress symptoms among children after the 2011 tsunami in Higashi-Matsushima, Japan. Brain Dev 2015;37:130-136.

80) Usami M, Iwadare $Y$, Kodaira M, Watanabe K, Aoki M, Katsumi C, et al. Relationships between traumatic symptoms and environmental damage conditions among children 8 months after the 2011 Japan earthquake and tsunami. PLoS One 2012;7:e50721.

81) Usami M, Iwadare Y, Kodaira M, Watanabe K, Aoki M, Katsumi C, et al. Sleep duration among children 8 months after the 2011 Japan earthquake and tsunami. PLoS One 2013;8:e65398.

82) Usami M, Iwadare $Y$, Watanabe $K$, Kodaira $M$, Ushijima $H$, Tanaka T, et al. Decrease in the traumatic symptoms observed in child survivors within three years of the 2011 Japan earthquake and tsunami. PLoS One 2014;9:e110898.

83) Goenjian AK, Roussos A, Steinberg AM, Sotiropoulou C, Walling D, Kakaki M, et al. Longitudinal study of PTSD, depression, and quality of life among adolescents after the Parnitha earthquake. J Affect Disord 2011;133:509-515.
84) Parvaresh N, Bahramnezhad A. Post-traumatic stress disorder in bam-survived students who immigrated to Kerman, four months after the earthquake. Arch Iran Med 2009;12:244-249.

85) Siriwardhana C, Pannala G, Siribaddana S, Sumathipala A, Stewart R. Impact of exposure to conflict, tsunami and mental disorders on school absenteeism: findings from a national sample of Sri Lankan children aged 12-17 years. BMC Public Health 2013;13: 560 .

86) McLaughlin KA, Fairbank JA, Gruber MJ, Jones RT, Lakoma MD, Pfefferbaum B, et al. Serious emotional disturbance among youths exposed to Hurricane Katrina 2 years postdisaster. J Am Acad Child Adolesc Psychiatry 2009;48:1069-1078.

87) McLaughlin KA, Fairbank JA, Gruber MJ, Jones RT, Osofsky JD, Pfefferbaum B, et al. Trends in serious emotional disturbance among youths exposed to Hurricane Katrina. J Am Acad Child Adolesc Psychiatry 2010;49:990-1000.

88) Wu CH, Chen SH, Weng LJ, Wu YC. Social relations and PTSD symptoms: a prospective study on earthquake-impacted adolescents in Taiwan. J Trauma Stress 2009;22:451-459.

89) Neuner F, Schauer E, Catani C, Ruf M, Elbert T. Post-tsunami stress: a study of posttraumatic stress disorder in children living in three severely affected regions in Sri Lanka. J Trauma Stress 2006; 19:339-347.

90) Nygaard E, Jensen TK, Dyb G. Stability of posttraumatic stress reaction factors and their relation to general mental health problems in children: a longitudinal study. J Clin Child Adolesc Psychol 2012;41:15-26.

91) Nygaard E, Jensen TK, Dyb G. Posttraumatic stress reactions in siblings after mutual disaster: relevance of family factors. J Trauma Stress 2010;23:278-281.

92) Hansel TC, Osofsky JD, Osofsky HJ, Friedrich P. The effect of long-term relocation on child and adolescent survivors of Hurricane Katrina. J Trauma Stress 2013;26:613-620.

93) McDermott B, Cobham V, Berry H, Kim B. Correlates of persisting posttraumatic symptoms in children and adolescents 18 months after a cyclone disaster. Aust N Z J Psychiatry 2014;48:80-86.

94) Madkour AS, Johnson CC, Clum GA, Brown L. Disaster and youth violence: the experience of school-attending youth in New Orleans. J Adolesc Health 2011;49:213-215.

95) Otto MW, Henin A, Hirshfeld-Becker DR, Pollack MH, Biederman J, Rosenbaum JF. Posttraumatic stress disorder symptoms following media exposure to tragic events: impact of 9/11 on children at risk for anxiety disorders. J Anxiety Disord 2007;21:888902.

96) McDermott BM, Palmer LJ. Postdisaster emotional distress, depression and event-related variables: findings across child and adolescent developmental stages. Aust N Z J Psychiatry 2002;36: 754-761.

97) Yule W, Udwin O, Murdoch K. The 'Jupiter' sinking: effects on children's fears, depression and anxiety. J Child Psychol Psychiatry 1990;31:1051-1061.

98) Yule W. Children in shipping disasters. J R Soc Med 1991;84:12-15.

99) Yule W, Udwin O. Screening child survivors for post-traumatic stress disorders: experiences from the 'Jupiter' sinking. Br J Clin Psychol 1991;30:131-138.

100) Gil-Rivas V, Silver RC, Holman EA, McIntosh DN, Poulin M. Parental response and adolescent adjustment to the September 11, 2001 terrorist attacks. J Trauma Stress 2007;20:1063-1068.

101) Gershoff ET, Aber JL, Ware A, Kotler JA. Exposure to $9 / 11$ among youth and their mothers in New York City: enduring associations with mental health and sociopolitical attitudes. Child Dev 2010; 81:1142-1160.

102) Broberg AG, Dyregrov A, Lilled L. The Göteborg discotheque fire: posttraumatic stress, and school adjustment as reported by the primary victims 18 months later. J Child Psychol Psychiatry 2005; 
46:1279-1286

103) Lengua LJ, Long AC, Smith KI, Meltzoff AN. Pre-attack symptomatology and temperament as predictors of children's responses to the September 11 terrorist attacks. J Child Psychol Psychiatry 2005;46:631-645

104) Lindstrom KM, Mandell DJ, Musa GJ, Britton JC, Sankin LS, Mogg K, et al. Attention orientation in parents exposed to the $9 / 11$ terrorist attacks and their children. Psychiatry Res 2011;187:261-266.

105) Yelland C, Robinson P, Lock C, La Greca AM, Kokegei B, Ridgway V, et al. Bushfire impact on youth. J Trauma Stress 2010;23: 274-277.

106) Fairbrother G, Stuber J, Galea S, Fleischman AR, Pfefferbaum B. Posttraumatic stress reactions in New York City children after the September 11, 2001, terrorist attacks. Ambul Pediatr 2003;3:304311.

107) Boer F, Smit C, Morren M, Roorda J, Yzermans J. Impact of a technological disaster on young children: a five-year postdisaster multiinformant study. J Trauma Stress 2009;22:516-524.

108) Papadatou D, Giannopoulou I, Bitsakou P, Bellali T, Talias MA, Tselepi K. Adolescents' reactions after a wildfire disaster in Greece. J Trauma Stress 2012;25:57-63.

109) Kerns CE, Elkins RM, Carpenter AL, Chou T, Green JG, Comer JS. Caregiver distress, shared traumatic exposure, and child adjustment among area youth following the 2013 Boston Marathon bombing. J Affect Disord 2014;167:50-55.

110) Hoven CW, Duarte CS, Lucas CP, Wu P, Mandell DJ, Goodwin RD, et al. Psychopathology among New York city public school children 6 months after September 11. Arch Gen Psychiatry 2005; 62:545-552

111) Pfefferbaum B, Stuber J, Galea S, Fairbrother G. Panic reactions to terrorist attacks and probable posttraumatic stress disorder in adolescents. J Trauma Stress 2006;19:217-228.

112) Duarte CS, Hoven CW, Wu P, Bin F, Cotel S, Mandell DJ, et al. Posttraumatic stress in children with first responders in their families. J Trauma Stress 2006;19:301-306.

113) Chemtob CM, Nomura Y, Josephson L, Adams RE, Sederer L. Substance use and functional impairment among adolescents directly exposed to the 2001 World Trade Center attacks. Disasters 2009;33:337-352.

114) Pfefferbaum B, Seale TW, McDonald NB, Brandt EN Jr, Rainwater SM, Maynard BT, et al. Posttraumatic stress two years after the Oklahoma City bombing in youths geographically distant from the explosion. Psychiatry 2000;63:358-370.

115) Mirzamani M, Mohammadi MR, Besharat MA. Post-traumatic stress disorder symptoms of children following the occurrence of Tehran City Park disaster. J Psychol 2006;140:181-186.

116) Pfefferbaum B, Nixon SJ, Tucker PM, Tivis RD, Moore VL, Gurwitch $\mathrm{RH}$, et al. Posttraumatic stress responses in bereaved children after the Oklahoma City bombing. J Am Acad Child Adolesc Psychiatry 1999;38:1372-1379.
117) Bolton D, O'Ryan D, Udwin O, Boyle S, Yule W. The long-term psychological effects of a disaster experienced in adolescence: II: general psychopathology. J Child Psychol Psychiatry 2000;41: 513-523.

118) McDermott BM, Lee EM, Judd M, Gibbon P. Posttraumatic stress disorder and general psychopathology in children and adolescents following a wildfire disaster. Can J Psychiatry 2005;50:137-143.

119) Comer JS, Dantowitz A, Chou T, Edson AL, Elkins RM, Kerns C, et al. Adjustment among area youth after the Boston Marathon bombing and subsequent manhunt. Pediatrics 2014;134:7-14.

120) Nordanger DØ, Hysing M, Posserud MB, Lundervold AJ, Jakobsen R, Olff M, et al. Posttraumatic responses to the July 22, 2011 Oslo Terror among Norwegian high school students. J Trauma Stress 2013;26:679-685.

121) Comer JS, Fan B, Duarte CS, Wu P, Musa GJ, Mandell DJ, et al. Attack-related life disruption and child psychopathology in New York City public schoolchildren 6-months post-9/11. J Clin Child Adolesc Psychol 2010;39:460-469.

122) Paasivirta ME, Duarte CS, Wu P, Bin F, Goodman RF, Brown EJ, et al. Factor structure of the Youth Coping In Traumatic Times (YCITT) scale. Psychiatry Res 2010;179:357-362.

123) Reijneveld SA, Crone MR, Verhulst FC, Verloove-Vanhorick SP. The effect of a severe disaster on the mental health of adolescents: a controlled study. Lancet 2003;362:691-696.

124) Shannon MP, Lonigan CJ, Finch AJ Jr, Taylor CM. Children exposed to disaster: I. epidemiology of post-traumatic symptoms and symptom profiles. J Am Acad Child Adolesc Psychiatry 1994;33: 80-93.

125) Piyavhatkul N, Pairojkul S, Suphakunpinyo C. Psychiatric disorders in tsunami-affected children in Ranong province, Thailand. Med Princ Pract 2008;17:290-295.

126) Kar N, Mohapatra PK, Nayak KC, Pattanaik P, Swain SP, Kar HC. Post-traumatic stress disorder in children and adolescents one year after a super-cyclone in Orissa, India: exploring cross-cultural validity and vulnerability factors. BMC Psychiatry 2007:7:8.

127) Vila G, Witkowski P, Tondini MC, Perez-Diaz F, Mouren-Simeoni MC, Jouvent R. A study of posttraumatic disorders in children who experienced an industrial disaster in the Briey region. Eur Child Adolesc Psychiatry 2001;10:10-18.

128) Li X, Huang X, Tan H, Liu A, Zhou J, Yang T. A study on the relationship between posttraumatic stress disorder in flood victim parents and children in Hunan, China. Aust N Z J Psychiatry 2010; 44:543-550.

129) Stoppelbein L, Greening L. Posttraumatic stress symptoms in parentally bereaved children and adolescents. J Am Acad Child Adolesc Psychiatry 2000;39:1112-1119.

130) Kumar M, Fonagy P. Differential effects of exposure to social violence and natural disaster on children's mental health. J Trauma Stress 2013;26:695-702. 